\title{
Aggregation-Induced Emission Properties of Triphenylamine Chalcone Compounds
}

\author{
Qi Teng \\ Lanzhou University of Technology

\section{Yun-Shang Yang} \\ Lanzhou University of Technology \\ Jing-Qi Cao \\ Lanzhou University of Technology \\ Ji-Jun Xue \\ Lanzhou University
}

ying-peng zhang ( $\nabla$ yingpengzhang@126.com )

Lanzhou University of Technology https://orcid.org/0000-0002-3873-4574

\section{Research Article}

Keywords: triphenylamine, Chalcone, AlE, Optoelectronics

Posted Date: February 18th, 2021

DOI: https://doi.org/10.21203/rs.3.rs-210960/v1

License: (c) (i) This work is licensed under a Creative Commons Attribution 4.0 International License. Read Full License

Version of Record: A version of this preprint was published at Journal of Fluorescence on March 16th, 2021. See the published version at https://doi.org/10.1007/s10895-021-02711-6. 


\section{Abstract}

Two triphenylamine chalcone derivatives 1 and 2 were synthesized through the Vilsmeier-Haack reaction and Claisen-Schmidt condensation reaction. Through ultraviolet absorption spectroscopy and fluorescence emission spectroscopy experiments, it was confirmed that these two compounds exhibited good aggregation-induced emission (AIE) behavior in ethanol/water mixtures. The solvent effect test showed with the increase of the orientation polarizability of the solvent, the Stokes shift in the solvent of compound 1 and compound 2 shows a linear change trend. Through solid state fluorescence test and universal density function theory (DFT), the existence of $\pi-\pi$ stacking interaction in the solid state of the compound has been studied, resulting in weak fluorescence emission. $\mathrm{pH}$ has no effect on the fluorescence intensity of the aggregate state of excited state intramolecular proton transfer (ESIPT) molecules in an acidic environment, but greatly weakens its fluorescence intensity in an alkaline environment. Cyclic voltammetry (CV) test shows that compound 1 was more prone to oxidation reaction than compound 2. The results of thermal stability test show that the thermal stability of compound 1 was better than that of compound 2, indicating that triphenylamine chalcone derivatives can improve the thermal stability of compounds by increasing the number of branches.

\section{Introduction}

In recent years, AIE materials have been widely used in chemical sensing, biological imaging, organic light-emitting diodes (OLED) ${ }^{[1-7]}$, etc...Based on a large number of experiments and theoretical studies, researchers have concluded that restriction of intramolecular rotations (RIR), excited state intramolecular proton transfer (ESIPT), etc. ${ }^{[8]}$ inhibits the $\pi-\pi$ accumulation in the molecule to achieve the AIE effect. Due to the widespread application of molecules based on the ESIPT mechanism of action ${ }^{[9-11]}$, the behavior of AIE based on the ESIPT mechanism has gradually gained attention in the field of natural sciences. Generally, a molecule with ESIPT characteristics was composed of a proton donor (such as -OH, $-\mathrm{NH}_{2}$ ) and a proton acceptor (such as $-\mathrm{N}=\mathrm{C}, \mathrm{C}=0$ ) ${ }^{[12]}$. Because of its $\pi$ conjugated framework, the fluorescence emission of 2-hydroxychalcone derivatives was often affected by aggregation-caused quenching (ACQ). Triphenylamine was a molecule with a central $\mathrm{N}$ atom and three benzene rings connected around it to form a star-shaped structure. Because of its special structure, it has larger steric hindrance and higher hole transport rate ${ }^{[13]}$. In addition, the structure of triphenylamine was easy to modified. Although the fluorescence emission efficiency of triphenylamine was not high, the modified triphenylamine derivatives were used in fluorescent probes ${ }^{[14-16]}$, organic electroluminescent materials and organic solar cell materials ${ }^{[17-18]}$ and other aspects have been widely used.

Recently, triphenylamine derivatives have also been extensively studied on AIE behavior ${ }^{[18-24]}$. Owing to the unique helical structure of triphenylamine, partial access of triphenylamine group to 2-

hydroxychalcone can effectively avoid face-to-face $\pi-\pi$ accumulation of molecules, inhibit the production of ACQ effects, and enhance its fluorescence in the aggregated state. However, the AIE effect will be affected by different solvents ${ }^{[25-28]}$, different substituents ${ }^{[29-32]}, \mathrm{pH}^{[33]}$, etc. In view of this, this paper 
designed and synthesized two triphenylamine chalcone derivatives with different substituents. Because of this, two triphenylamine chalcone derivatives containing different substituents were designed and synthesized, and their AIE behavior was studied in different solvents and ethanol/water mixtures.

\section{Experimental}

\section{Materials and methods}

The raw materials required for the experiment such as triphenylamine, phosphorusvoxychloride, N,Ndimethylformamide, 2-hydroxyacetophenone, 2-hydroxy-1-naphthophenone, sodium hydroxide, ethanol, and chloroform. ${ }^{1} \mathrm{H}$ and ${ }^{13} \mathrm{C}$-NMR spectra were recorded on a Avance 400 spectrometer in $\mathrm{CDCl}_{3}$ with

TMS as an internal standard. Mass spectrum was recorded on the Thermo Q-Exactive mass spectrometer. The melting point was measured on the XRC-1 $\mu$ melting point instrument. The ultraviolet absorption was recorded on Cary50. The fluorescence test was recorded on the FE06CN-IF171(ZB) LD/LM luminescence spectrophotometer. Thermogravimetric analysis (TGA) was performed on Mettler $\mathrm{STAR}^{\mathrm{e}}$ System thermal analyser under nitrogen flushing at a heating rate of $10{ }^{\circ} \mathrm{C} \mathrm{min}{ }^{-1}$ with sample weight of 3-4 mg. Cyclic voltammetry measurements were performed on a $\mathrm{CHI} 660 \mathrm{E}$ electrochemical workstation at room temperature with three electrodes cell system in a solution of $\mathrm{Bu}_{4} \mathrm{NPF}_{6}(0.1 \mathrm{M})$ in chloroform at a scanning rate of $100 \mathrm{mVs}^{-1}$. Glassy carbon electrode acts as working electrode; platinum electrode used as a counter electrode and SCE (saturated calomel electrode) electrode as a reference electrode. The scanning electron microscope images of compound 1 and compound 2 in different ratios of ethanol and water as solvents were tested on Hitachi Regulus 8100 high-resolution cold field emission electron microscope.

\section{Synthesis of chalcone compounds}

4-Diphenylaminobenzaldehyde and 4,4'-diformyltrianiline were synthesized according to literature ${ }^{\text {[34] }}$. The chalcone compound was synthesized according to literature ${ }^{[35]}$. 4,4'-dimethylacyl-trianiline (10 $\mathrm{mmol})$ and 2-hydroxyacetophenone $(20 \mathrm{mmol})$ were dissolved in $50 \mathrm{ml}$ anhydrous ethanol, The reaction temperature was controlled below $7{ }^{\circ} \mathrm{C}$ and slowly add $2 \mathrm{ml} \mathrm{NaOH}(21 \mathrm{M})$ solution to the reaction system. After reaction was stirred for $24 \mathrm{~h}$ at $25^{\circ} \mathrm{C}$, the pure product was obtained by silica gel

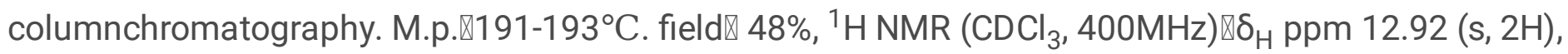
$7.91(\mathrm{~d}, \mathrm{~J}=4 \mathrm{~Hz}, 3 \mathrm{H}), 7.87(\mathrm{~s}, 1 \mathrm{H}), 7.57(\mathrm{~d}, \mathrm{~J}=2 \mathrm{~Hz}, 3 \mathrm{H}), 7.56(\mathrm{~s}, 2 \mathrm{H}), 7.54(\mathrm{~s}, 1 \mathrm{H}), 7.48(\mathrm{t}, \mathrm{J}=4 \mathrm{~Hz}, 2 \mathrm{H}), 7.36(\mathrm{t}$, $\mathrm{J}=4 \mathrm{~Hz}, 2 \mathrm{H}), 7.19(\mathrm{~s}, \mathrm{~J}=4 \mathrm{~Hz}, 3 \mathrm{H}), 7.14(\mathrm{~s}, 2 \mathrm{H}), 7.12(\mathrm{~s}, 2 \mathrm{H}), 7.03(\mathrm{~s}, 1 \mathrm{H}), 7.01(\mathrm{~s}, 1 \mathrm{H}), 6.93(\mathrm{t}, \mathrm{J}=4 \mathrm{~Hz}, 2 \mathrm{H}) .{ }^{13} \mathrm{C}$ $\operatorname{NMR}\left(\mathrm{CDCl}_{3}, 100 \mathrm{MHz}\right) \otimes \delta_{\mathrm{C}} \mathrm{ppm} 193.48,163.56,149.38,146,144.82,136.19,130.09,129.85,129.47$, $129.10,126.31,125.32,123.31,120.12,118.77,118.60,118.16$. HRMS m/z: calculated for $[\mathrm{M}+\mathrm{H}]^{+} 20$, found 538.20144 .

5-Diphenylaminobenzaldehyde $(10 \mathrm{mmol})$ and 2-hydroxy-1-naphthaleneethanone $(10 \mathrm{mmol})$ were dissolved in $50 \mathrm{ml}$ of absolute ethanol. Then slowly added2 $\mathrm{ml} \mathrm{NaOH}(25 \mathrm{M})$ solution to the reaction 
system under ice water, reacted ov-ernight at room temperature, and then purified by column chromatography to obtain compound 2. M.p: $191-193^{\circ} \mathrm{C}$. field $\nabla 53 \%,{ }^{1} \mathrm{H} \mathrm{NMR}\left(\mathrm{CDCl}_{3}, 400 \mathrm{MHz}\right) \otimes \delta_{\mathrm{H}} \mathrm{ppm}$ $12.60(\mathrm{~s}, 1 \mathrm{H}), 8.08(\mathrm{~d}, \mathrm{~J}=4 \mathrm{~Hz}, 1 \mathrm{H}), 7.89(\mathrm{t}, \mathrm{J}=4 \mathrm{~Hz}, 2 \mathrm{H}), 7.79(\mathrm{~d}, \mathrm{~J}=4 \mathrm{~Hz}, 1 \mathrm{H}), 7.52(\mathrm{t}, \mathrm{J}=4 \mathrm{~Hz}, 1 \mathrm{H}), 7.46(\mathrm{~d}$, $\mathrm{J}=4 \mathrm{~Hz}, 2 \mathrm{H}), 7.38(\mathrm{t}, \mathrm{J}=4 \mathrm{~Hz}, 2 \mathrm{H}), 7.34(\mathrm{~s}, 1 \mathrm{H}), 7.30(\mathrm{t}, \mathrm{J}=4 \mathrm{~Hz}, 4 \mathrm{H}), 7.18(\mathrm{~s}, 1 \mathrm{H}), 7.15(\mathrm{t}, \mathrm{J}=4 \mathrm{~Hz}, 4 \mathrm{H}), 7.11(\mathrm{t}$, $\mathrm{J}=4 \mathrm{~Hz}, 2 \mathrm{H}), 7.02(\mathrm{~d}, \mathrm{~J}=2 \mathrm{~Hz}, 2 \mathrm{H}) .{ }^{13} \mathrm{C} N M R\left(\mathrm{CDCl}_{3}, 100 \mathrm{MHz}\right) \otimes \delta_{\mathrm{C}} \mathrm{ppm} 194.34,162.37,150.39,146.67$, $143.13,136.33,131.57,130.03,129.54,129.20,128.63,127.62,127.52,125.61,125.20,124.31,124.22$, $123.80,121.29,119.39,116.13$. HR-MS m/z: calculated for $[M+H]^{+} 442.18$, found 442.18012 .

\section{Results And Discussion}

\section{Solvent effect}

In order to investigate the influence of different solvents on the ESIPT behavior of compound 1 and compound 2, the UV-visible absorption spectrum and fluorescence emission spectrum behavior of compound 1 and compound 2 in acetone, ethanol, dichloromethane, tetrahydrofuran, toluene, and chloroform were studied. It can be seen from Figure 2(a) and 2.(b) that the absorption wavelength was shorter in the protic solvent ethanol. The absorption wavelength was longer in aprotic solvents. As was shown in Figure 2(c), the maximum emission peak of fluorescence spectrum gradually shifted to long wavelength in toluene, chloroform, tetrahydrofuran, dichloromethane and acetone. In the Figure 2(d), this change is not observed, which may be caused by different substituents on the triphenylamine group. To understand the effect of solvent polarity on the optical properties of substances, the relationship between the oriented polarizability $(\Delta \mathrm{f})$ and the corresponding stokes shift $\left(\Delta \mathrm{v} \mathrm{cm}{ }^{-1}\right)$ of toluene, chloroform, dichloromethane, tetrahydrofuran and ethanol solvents was studied ${ }^{[36]}$. From Figure 3 and Table S1, it can be seen that with the increase of the orientation polarizability of the solvent, the Stokes shift in the solvent of compound 1 and compound 2 shows a linear change trend ${ }^{[37]}$.

$$
\begin{aligned}
& \Delta \mathrm{v}=\mathrm{v}_{\mathrm{abs}}-\mathrm{v}_{\mathrm{flu}}=\frac{2 \Delta \mu^{2}}{h c a^{3}} \Delta f+\text { constant } \\
& \Delta \mathrm{f}=\frac{\varepsilon-1}{2 \varepsilon+1}-\frac{\eta^{2}-1}{2 \eta^{2}+1}
\end{aligned}
$$

Where, the $\mathrm{v}_{\mathrm{abs}}$ and $\mathrm{v}_{\mathrm{flu}}$ are the wavelengths corresponding to the peak of the absorption and emission spectra, respectively. the $\mathrm{h}$ was the planck constant, the $\mathrm{c}$ was the speed of light, and the a was the cavity radius. $\Delta \mu$ was the difference between the excited state dipole moment and the ground state dipole moment. $\varepsilon$ and $\eta$ were the dielectric constant and the refractive index of the solvent, respectively.

\section{AlE behavior}


Chalcone compounds were soluble in ethanol solution and insoluble in water. In order to study whether compound 1 and compound 2 have aggregation-induced emission behavior, the UV absorption spectra and fluorescence emission spectra of chalcone compounds 1 and 2 in different proportions of ethanol/water mixtures were studied. As shown in Figure 4(a), with the increase of water volume fractions in ethanol/ water mixtures, compounds 1 and 2 show different degrees of decrease of absorption intensity and horizontal trailing phenomenon. The reason for the decrease of absorption intensity may be the light scattering of suspension in aggregate state ${ }^{[38]}$.

Meanwhile, the change of fluorescence intensity caused by the volume content of different water in ethanol/water mixtures was determined. As shown in Figure 4.(b), when the volume fraction of water in the ethanol/water mixtures of Compound 1 was less than $40 \%$, the fluorescence intensity was not change substantially. When the volume fraction of water was higher than $40 \%$, the fluorescence intensity gradually increases. As shown in Figure 5, Compound 2 exhibited similar behavior to compound 1 in ethanol/water mixtures. When the volume fractions of water in ethanol/water mixtures was less than $50 \%$, the fluorescence intensity was very weak. It may be due to the free rotation of the sigma bond of the benzene ring in the molecule and the distortion of the charge transfer in the molecule, which leads to the destruction of the proton transfer in the excited state ${ }^{[39]}$. When the volume fractions of water in the ethanol/water mixtures was higher than $50 \%$, the gradual increase in fluorescence intensity may be due to the carbonyl structure $(-\mathrm{C}=\mathrm{O})$ on the chalcone group and the hydroxyl structure $(-\mathrm{OH})$ on the benzene ring undergo an excited state intramolecular proton transfer to form a stable hydrogen bond in aggregate state, which inhibits free rotation within the molecule and enhances fluorescence ${ }^{[40,41]}$. Meanwhile, the fluorescence emission behavior of compound 1 and compound 2 in the solid state was also studied. As was shown in Figure 6, the emission peaks of Compound 1 and Compound 2 in the solid state were 610 $\mathrm{nm}$ and $620 \mathrm{~nm}$, respectively. While compounds 1 and 2 had emission peaks of $550 \mathrm{~nm}$ and $541 \mathrm{~nm}$ in ethanol solvent, respectively. The fluorescence maximum emission peak in the solid state has a red shift of $60 \mathrm{~nm}$ and $79 \mathrm{~nm}$, respectively, relative to the fluorescence maximum emission peak in ethanol solvent. It was caused by the $\pi-\pi$ stacking between molecules in the solid state. As was shown in Figure 7, Under $365 \mathrm{~nm}$ UV light, the solid state emission of compound 1 was weaker than (E)-3-(4-

(diphenylamino)phenyl)-1-(2-hydroxyphenyl)prop-2-en-1-one reported in literature ${ }^{\text {[42] }}$. This phenomenon was due to the increase of $\pi$-conjugated system, which causes the increase of $\pi-\pi$ stacking.

\section{Research on pH responsiveness}

In order to evaluate the effect of $\mathrm{pH}$ on the aggregation state of ESIPT molecules, the $\mathrm{pH}$ responsiveness of it was studied in an ethanol/water mixtures $\left(f_{\mathrm{w}}=90 \%\right)$. As was shown in figure 8 , when the $\mathrm{pH}$ was less than 7, compound 1 and compound 2 were maintained in a stable range, without causing much change in fluorescence intensity. It was because the chalcone phenol hydroxyl group was acidic as an acidic proton donor and was insensitive to $\mathrm{pH}$ under acidic conditions. When the $\mathrm{pH}$ was greater than 7 , the fluorescence intensity of compounds 1 and 2 decreased significantly with the increase of $\mathrm{pH}$. It was because the increase of $\mathrm{OH}^{-}$in the solution deprives the hydrogen protons on the phenolic hydroxyl group, 
making it unable to form a stable hydrogen bond, resulting in low fluorescence intensity in the aggregate state.

\section{Theoretical calculation}

In order to have a comprehensive understanding of compound 1 and compound 2 at the molecular level, Gaussian09 software was used to optimize the structure of compounds 1 and 2 with B3LYP/6-31G(d) as the method and basis set. As was shown in figure 9, the electron cloud of the highest occupied molecular orbital (HOMO) of compound 1 and compound 2 was mainly distributed in the triphenylamine part, and the electron cloud of the lowest unoccupied molecular orbital (LUMO) was mainly distributed in the corresponding chalcone part. The calculated energy values of the $\mathrm{HOMO}$ and LUMO of compound 1 were $-5.11 \mathrm{eV}$ and $-1.95 \mathrm{eV}$, respectively. The energy values of HOMO and LUMO of compound 2 were $-5.20 \mathrm{eV}$ and $-2.21 \mathrm{eV}$, respectively. The HOMO-LUMO energy gap ( $\Delta \mathrm{Eg}$ ) of compound 1 and compound 2 were $3.16 \mathrm{eV}$ and $2.99 \mathrm{eV}$, respectively. It can be seen from the figure that the optimized spatial configuration of the molecule tends to be planar and fails to effectively prevent $\pi-\pi$ stacking, so the fluorescence emission in the solid state was weak.

\section{Electrochemical and optical properties}

The electrochemical behavior of compound 1 and compound 2 was carried out with $\mathrm{CHCl}_{3}$ as the solvent and tetrabutylammonium hexafluorophosphate as the supporting electrolyte, the electrochemical window is from $-1.8 \mathrm{~V}$ to $1.8 \mathrm{~V}$, and the scanning speed was $100 \mathrm{mV} / \mathrm{s}^{[43]}$. As was shown in figure $10(\mathrm{~b})$, the formation of the oxidation peak may be due to the electron donation of triphenylamine. The initial oxidation potentials of compound 1 and compound 2 were $1.06 \mathrm{~V}$ and $1.08 \mathrm{~V}$, respectively.

The initial oxidation potential of compound 1 was slightly lower than that of compound 2, indicating that compound 1 was easier to oxidize than compound 2. Calculated by the formula $E_{\text {HOMO }}=-e\left(E_{\text {onset }}{ }^{\mathrm{ox}}+4.4\right)$ $(\mathrm{eV})$, the potentials of the highest occupied molecular orbitals of compound 1 and compound 2 were $-5.46 \mathrm{~V}$ and $-5.48 \mathrm{~V}$, respectively. Compound 1 and compound 2 were dissolved in chloroform solution, the abscissa of the intersection of the initial line of the absorption wavelength and the long-range absorption spectrum measured by the UV-visible spectrometer was the initial incident wavelength $\lambda_{\text {onset. }}$. Then calculated the energy value of the optical band gap by the formula $E_{o p t}=1240 / \lambda_{\text {onset. }}$. The potential of the lowest unoccupied molecular orbital of compound and compound 2 was obtained according to the formula $\mathrm{E}_{\mathrm{LUMO}}=\mathrm{E}_{\mathrm{HOMO}}+\mathrm{E}_{\mathrm{opt}}(\mathrm{eV})$. The energy values $\left(\mathrm{E}_{\mathrm{opt}}\right)$ of the optical band gap of compound 1 and compound 2 were $2.24 \mathrm{~V}$ and $2.35 \mathrm{~V}$, respectively, which may be caused by the different degree of molecular conjugation ${ }^{[44]}$.

Table 2. Electrochemical properties, optical properties 


\begin{tabular}{|c|c|c|c|}
\hline \multirow{3}{*}{$\begin{array}{l}\text { Chalcone } \\
\text { Compound }\end{array}$} & $\mathrm{CV}$ & \multicolumn{2}{|l|}{ UV } \\
\hline & HOMO/LUMO $E_{\text {onset }}^{\text {ox }}$ & $\lambda_{\text {onset }}$ & \\
\hline & $(\mathrm{eV}) \quad(\mathrm{V})$ & $(\mathrm{nm})$ & $(\mathrm{eV})$ \\
\hline 1 & $-5.46 /-3.22 \quad 1.06$ & 553 & 2.24 \\
\hline 2 & $-5.48 /-3.13 \quad 1.08$ & 528 & 2.35 \\
\hline
\end{tabular}

\section{Thermal stability}

In order to study the thermal stability of compound 1 and compound 2, the two compounds were tested by thermogravimetric analysis. The $10 \%$ loss of compound mass was defined as the initial value of the thermal decomposition temperature. As was shown in the figure 11, the initial thermal decomposition temperature $\left(T_{d}\right)$ of compound 1 and compound 2 were $410^{\circ} \mathrm{C}$ and $340^{\circ} \mathrm{C}$, respectively. The initial thermal decomposition temperature of compound 1 was higher than that of compound 2, indicating that the derivatives of triphenylamine chalcone can be increased by the number of branches to improve thermal stability. These test results showed that compound 1 and compound 2 have good thermal stability.

\section{Conclusion}

Two triphenylamine chalcone derivatives were synthesized in this chapter, which showed good AIE behavior in ethanol/water mixtures, respectively. The Stokes shift of the solvent shows a linear trend with the increase of the solvent orientation polarizability. Different $\mathrm{pH}$ environments will affect the fluorescence intensity of the compound in the aggregate state. Both the solid state fluorescence test and the generalized density function theory show that the two compounds have $\pi-\pi$ stacking effect in solid state, which makes the fluorescence emission weak in solid state. Compound 1 is more prone to oxidation than compound 2 , and the thermal stability was better than compound 2 .

\section{Declarations}

\section{Funding}

Not applicable

\section{Conflict of interest}

The authors declare that they have no conflict of interest

\section{Availability of data and material}


The ${ }^{1} \mathrm{H}$ NMR, ${ }^{13} \mathrm{C}$ NMR HR-ESI-Ms of the 1 and 2 are detailed in the Supporting information. These materials are available free of charge via the Internet.

\section{Code availability}

Not applicable

\section{Author contributions:}

Ying-Peng Zhang, contributed to the conception of the study;

Qi Teng, performed the experiment;

Yun-Shang Yang, contributed significantly to analysis and manuscript preparation;

Jing-Qi Cao, performed the data analyses and wrote the manuscript;

Ji-Jun Xue, helped perform the analysis with constructive discussions.

\section{References}

[1] Z. Xie, C. Chen, S. Xu, J. Li, Z. Chi. Angew. Chem. Int. Ed. 2015, 127, 7287.

[2] J. Sun, Y. Lu, L. Wang, D. Cheng, Y. Sun, X. Zeng. Polym. Chem. 2013, 4, 4045.

[3] J. Huang, Y. Jiang, Yang, R. Tang, N. Xie, Q. Mater. Chem. 2014, 2, 2028.

[4] M. Liu, X. Zhang, B. Yang, L. Liu, F. Deng, X. Zhang, Y. Wei. Macromolecular. 2015, 14, 1260.

[5] R. Jiang, M. Cao, M. Liu, L. Liu, Q. Huang, H. Huang, Y. Wen, Q. Y. Cao, X. Zhang, Y. Wei. Mater. Sci. Eng. C. 2018, 92, 61 .

[6] Niu, R. Zhang, X. Shi, H. Park, B. Z. Tang. TrAC Trend. Anal. Chem. 2019, 123, 115769.

[7] M. Mohan, J. James, M. N. Satyanarayan, D. R. Trivedi, Luminescence 2019, 34, 715.

[8] W. Yang, C. C. Li, M. M. Zhang, W. Q. Zhou, R.Y. Xue, H. Li. Liu, Y. Y. Li. Phys. Chem. Chem. Phys. 2016, $18,28052$.

[9] M. Mathivanan, B. Tharmalingam, C. H. Lin, B. V. Pandiyan, V. Thiagarajan, B. Cryst. Eng. Comm. 2020, 22, 213.

[10] A. Felouat, M. Curtil, J.Massue, G.Ulrich. New J. Chem. 2019, 43, 9162.

[11] J. Zhou, R. Shi, J. Liu, R. Wang, Y. Xu, X. Qian. Org. Biomol. Chem. 2015, 13, 5344.

[12] Y. Q. Li, Y. Z. Ma, Y. F. Yang, W. Shi, R. F. Lan. Phys. Chem. Chem. Phys. 2018, 20, 4208.

[13] H. Zhang, Y. Qu, Y. T. Gao, J. L. Hua, J. Li, B. Li. Tetrahedron Lett. 2013, 54, 909. 
[14] B. Dumat, E. Faurel-Paul, P. Fornarelli, N. Saettel, G. Metge, C. Fiorini-Debuisschert, F. charra, F. Mahuteau-Betzer, M-P, Teulude-Fichou. Org. biomol. Chem. 2016, 14, 358.

[15] Q. Li, Z.Wang, W. Song, H. Ma, J. Dong, Y. Y. Quan, X. Ye, Z. S. Huang. Dyes. Pigm. 2019, 161, 389.

[16] J. L. Yin, M. Peng, Y. Y. Ma, R. Guo, W. Y. Lin. Chem. Commun. 2018, 54, 12093.

[17] L. Kong, J. Yang, H. Zhou, S. L, F. Hao, Q. Zhang, Y. Tu, J. Wu, Z. Xue, Y. Tian. Science Chinachemistry. 2013, 56, 106.

[18] Y. Wang, C. Yang, B. Li, F. Shi, Y. Gao, Z. Wang, J. Hua, Y. Chen, H. Peng. Optik. 2018, 167, 80.

[19] M. D.Yang, D. L. Xu, W. G. Xi, L. K. Wang, J. Zheng, J. Huang, J. Y. Zhang, H. P. Zhou,J. Y. Wu, Y. P. Tian. Org. Chem. 2013, 78, 10344.

[20] M. M. Zhang, W. Yang, T. F. Gong, W. Q. Zhou, R. Y. Xue. Phys. Chem. Chem. Phys. 2017, 19, 21672.

[21] T. Usuki, M. Shimada, Y. Yamanoi, T. Ohto, H. Tada, H. Kasai, E. Nishibori, H. Nishihara. ACS Appl. Mater. Interfaces. 2018, 10, 12164.

[22] G. L. Niu, X. L. Zheng, Z. Zhao, H. K. Zhang, J. G. Wang, X. W. He, Y. C. Chen, X. J. Shi, C. Ma, R. T. K. Kwok, J. W. Y. Lam, H. H. Y. Sung, I. D. Williams, K. S. Wong, P. F. Wang, B. Z. Tang. J. Am. Chem. Soc. 2019, 141, 15111.

[23] X. Wang, G. Ding, Y. Duan, Y. Zhu, C. H. Hung. Talanta. 2020, 217, 121029.

[24] H. r. Cheng, Y. Ji, F. Liu, X. j. Lu, Luminescence 2019, 34, 903.

[25] M. A. Satam, R. D. Telore, N. Sekar. Spectrochimica Acta Part a-Molecular and Biomolecular Spectroscopy. 2014, 132, 678.

[26] H. Matsumoto, S. Ikedu, T. Tosaka, Y. Nishimura, T. Arai. Photochem. Photobiol. Sci. 2018, 17, 561.

[27] Y. P. Chen, Y. F.Yang, Y. Zhao, S. X. Liu, Y. Q. Li. Phys. Chem. Chem. Phys. 2019, 21, 17711.

[28] Y. T. Qi, M. H. Lu, Y. Wang, Z. Tang, Z. Q. Gao, J. Tian, X. Fei, Y. Li, J. Y. Liu. Organic Chemistry Frontiers. 2019, 6, 3136.

[29] S. Ding, A. Xu, A. Sun, Y. Xia, Y. Liu. Spectrochimica acta. Part A, Molecular and biomolecular spectroscopy 2020, 245, 118937.

[30] M. Ni, S. Y. Su, H. Fang. J. Mol. Model. 2020, 26, 10.

[31] A. Chrayteh, C. Ewels, D. Jacquemin. Phys. Chem. Chem. Phys. 2020, 22, 854.

[32] N. N. Zhang, G. J. Liu, J. Y. Yan, T. T. Zhang, X. Liu. Dyes. Pigm. 2020, 175, 7. 
[33] L. Yan, T. Qing, R. Li, Z. Wang, Z. Qi. RSC Adv. 2016, 6, 63874.

[34] H. C. Zhu, J. Y. Huang, L. Kong, Y. P. Tian, J. X. Yang. Dyes. Pigm. 2018, 151, 140.

[35] H. Y. Jin, X. G. Li, T. F.Tan, S. R.Wang, Y. Xiao, J. H.Tian. Dyes. Pigm. 2014, 106, 154.

[36] E. Bozkurt, H. I. Gul, E. Mete. J. Photochem. Photobiol. A. chem. 2018, 352, 35.

[37] M. A. Satam, R. D. Telore, A. B. Lathe, V. D. Gupta, N. Sekar. Spectrochimica Acta Part a-Molecular and Biomolecular Spectroscopy. 2014, 127, 16.

[38] Q. Feng, Y. Li, K. Li, J. Lu, J. Wang, P. Fan, D. Li, D. Wu, H. Hou. Chemistryselect. 2017, 2, 3158.

[39] H. Fang, N. Wang, L. Xie, P. C. Huang, K. Y. Deng, F. Y. Wu. Sens. Actuator B-Chem. 2019, 294, 69.

[40] C. S. Liang, S. M. Jiang. Analyst. 2017, 142, 4825.

[41] S. Sharma, T. S. Virk, C. P. Pradeep, A. Dhir. European Journal of Inorganic Chemistry. 2017, 18, 2457.

[42] R. Li, L. Yan, Z. Wang, Z. Qi. J. Mol. Struct. 2017, 1136, 1.

[43] G. Chen, H. Y. Wang, Y. Liu, X. P. Xu, S. J. Ji. Dyes. Pigm. 2010, 85, 194.

[44] S. Revoju, S. Biswas, B. Eliasson, G. D. Sharma. Phys. Chem. Chem. Phys. 2018, 20, 6390.

\section{Figures}

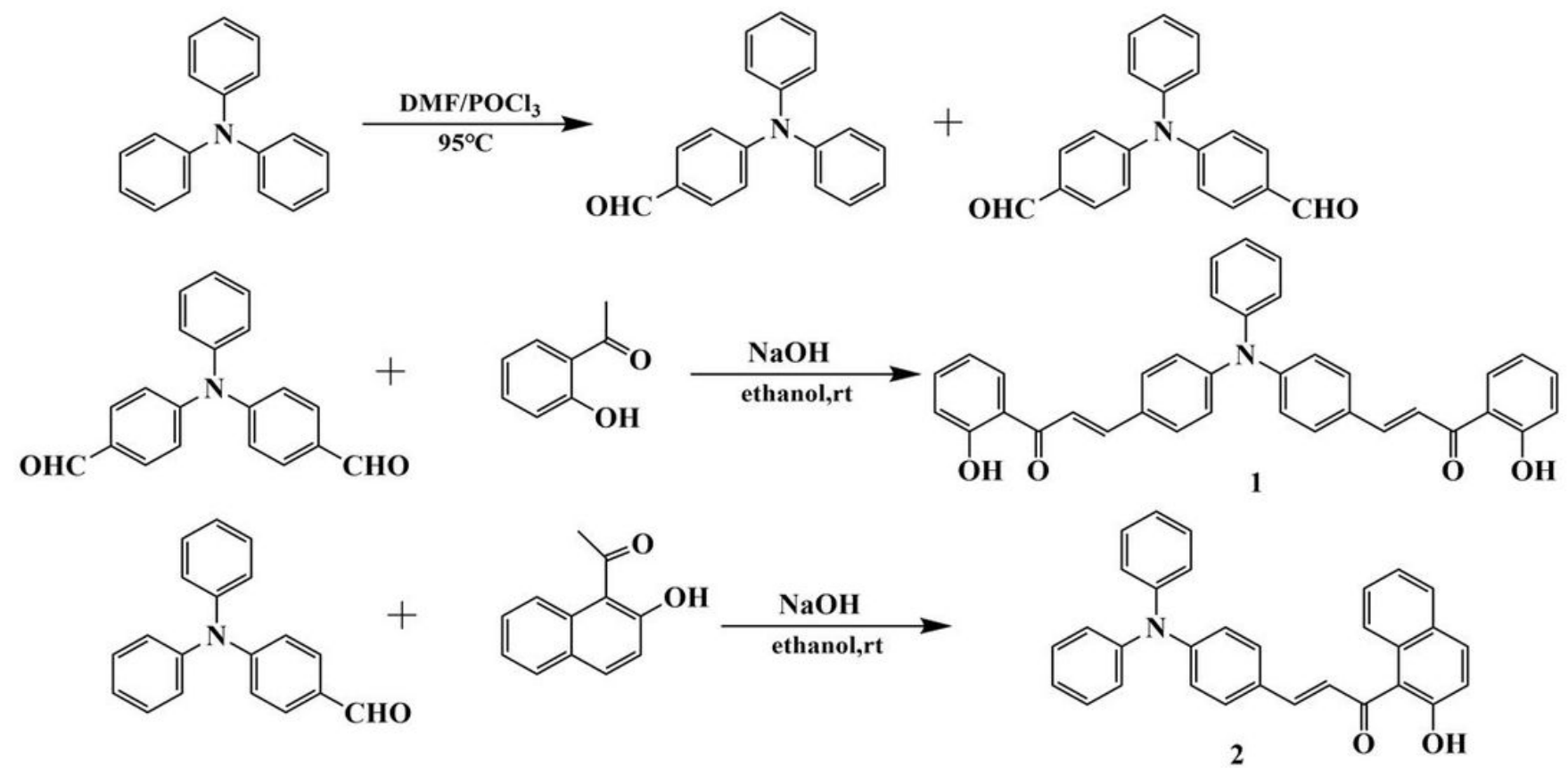


Figure 1

Synthesis routes of compounds 1 and 2
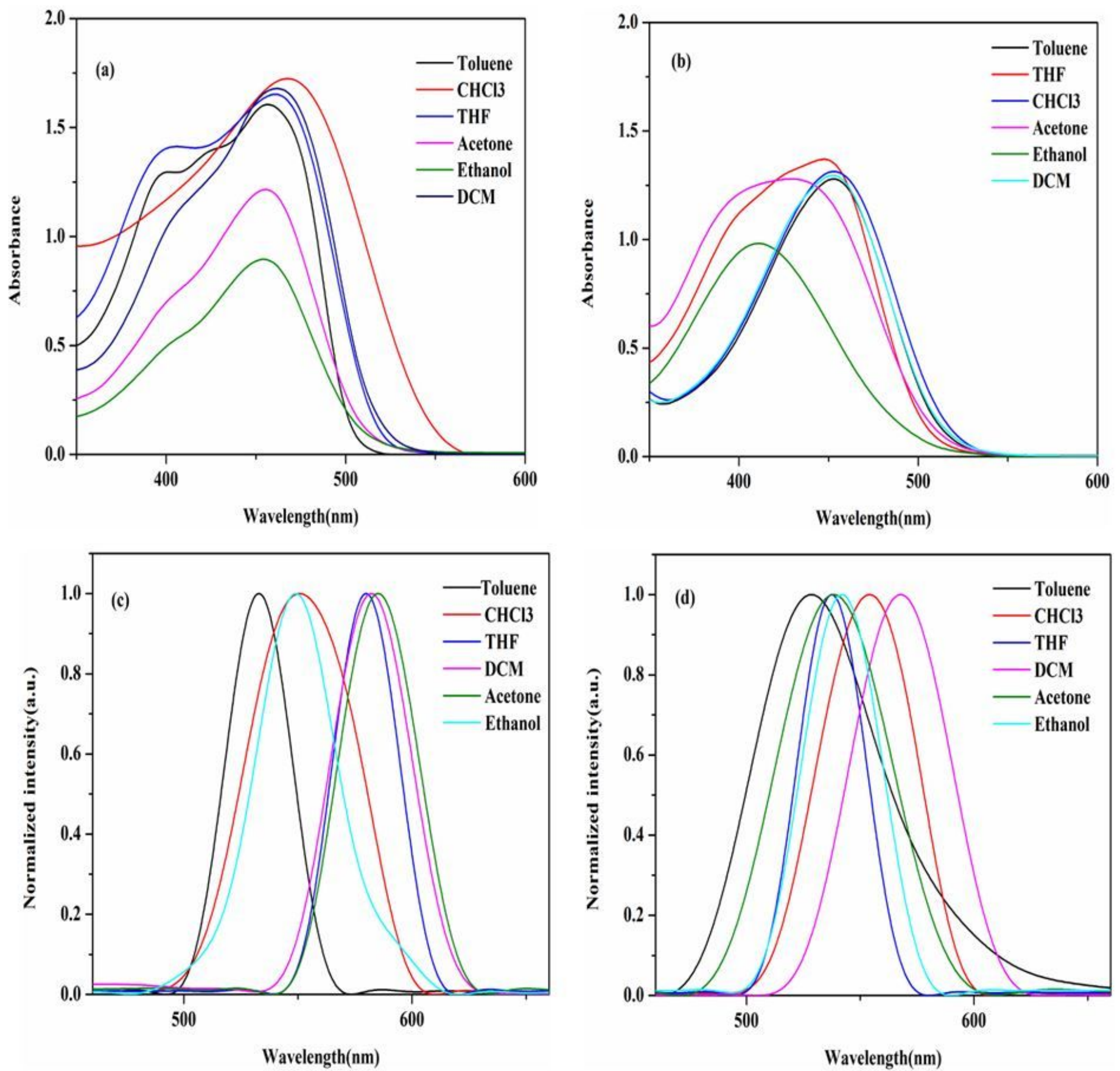

Figure 2

(a) UV-Vis absorption spectra of compound 1 under different solvents ( $c=1 \times 10-5 \mathrm{~mol} / \mathrm{L})$; (b) UV-Vis absorption spectra of compound 2 under different solvents (c=1×10-5 mol/L); (c) Normalized fluorescence emission spectra of compound 1 under different solvents (c=1×10-5 mol/L); (d) Normalized fluorescence emission spectra of compound 2 under different solvents $(c=1 \times 10-5 \mathrm{~mol} / \mathrm{L})$ 


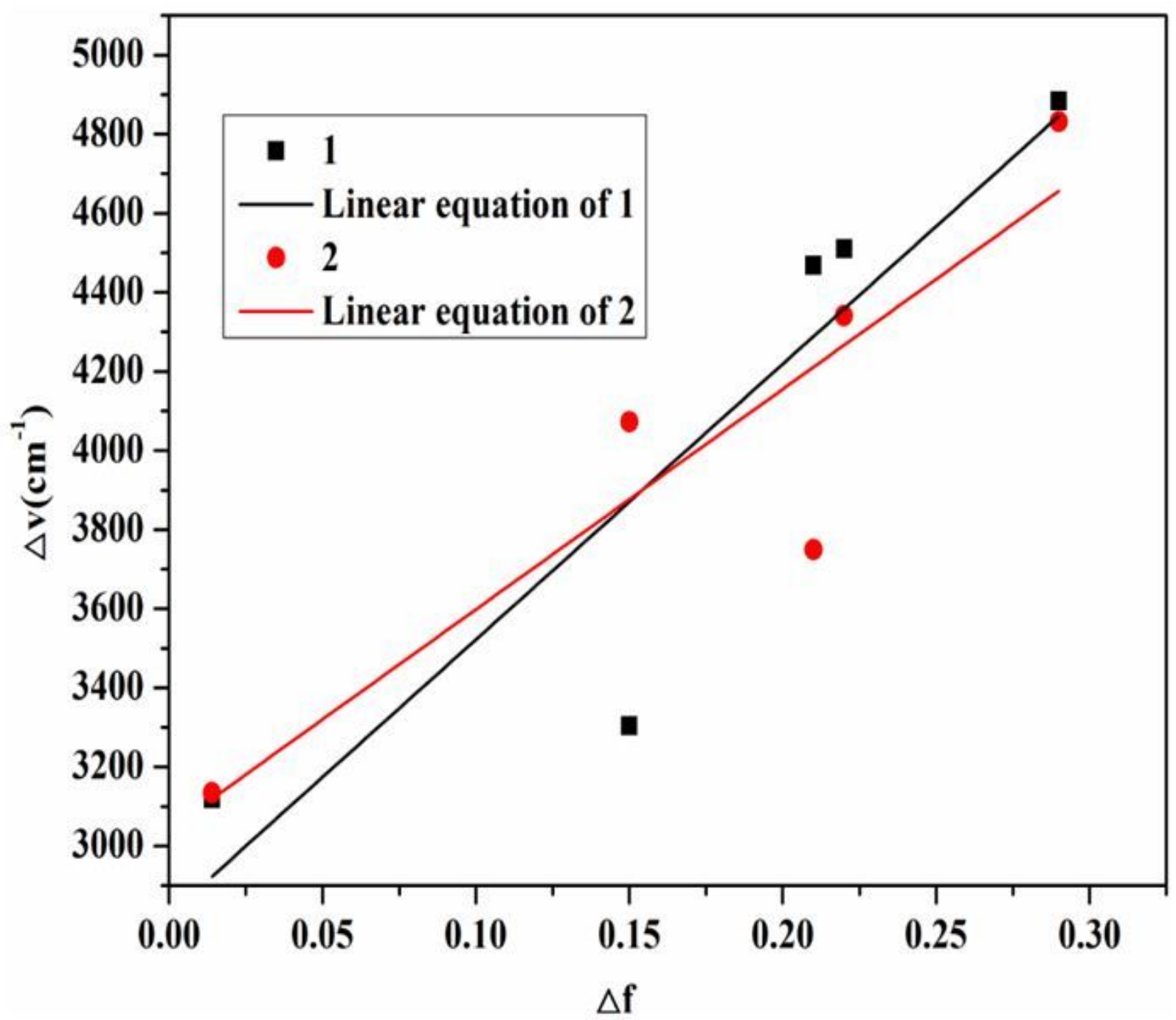

Figure 3

Lippert mataga plot of compounds 1 and 2 in different solvents 

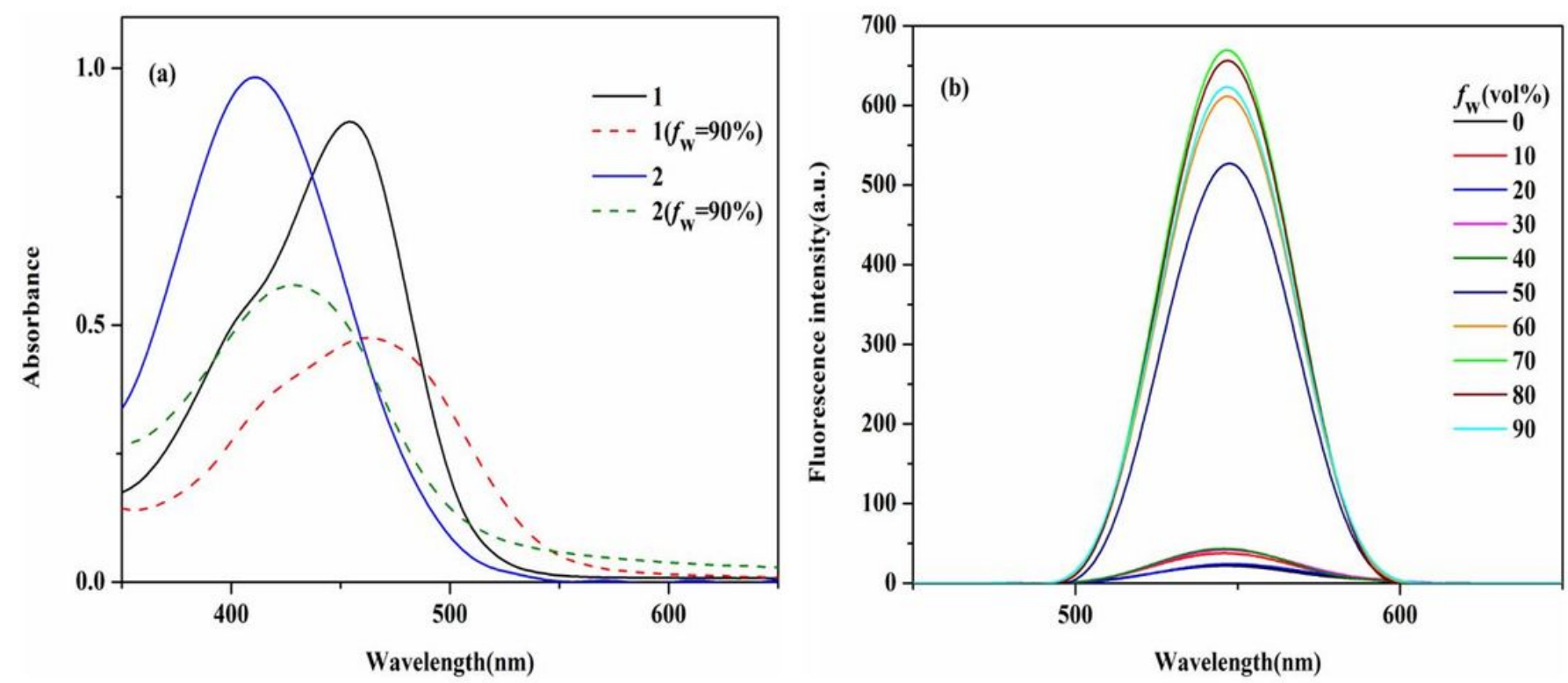

\section{Figure 4}

(a) UV-Vis absorption spectra of compounds 1 and 2 under volume fraction ( $\mathrm{fw}$ ) of different water in ethanol/water mixtures; (b) Fluorescence emission spectra of compound 1 in ethanol/water mixtures with different volume fractions of water ( $\mathrm{fw}$ ). 


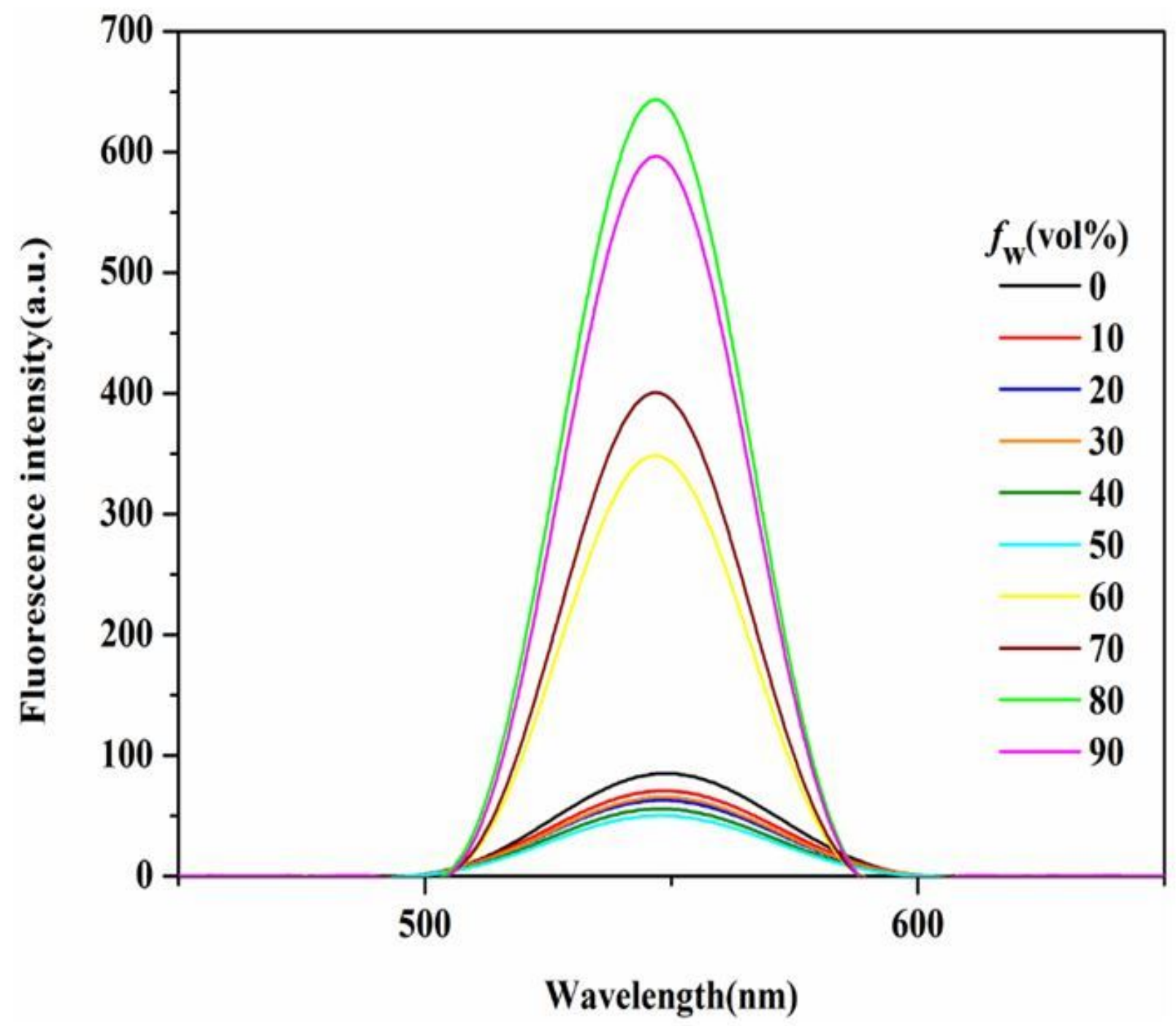

Figure 5

Fluorescence emission spectra of compound 2 in ethanol/water mixtures with different volume fractions of water (fw) 


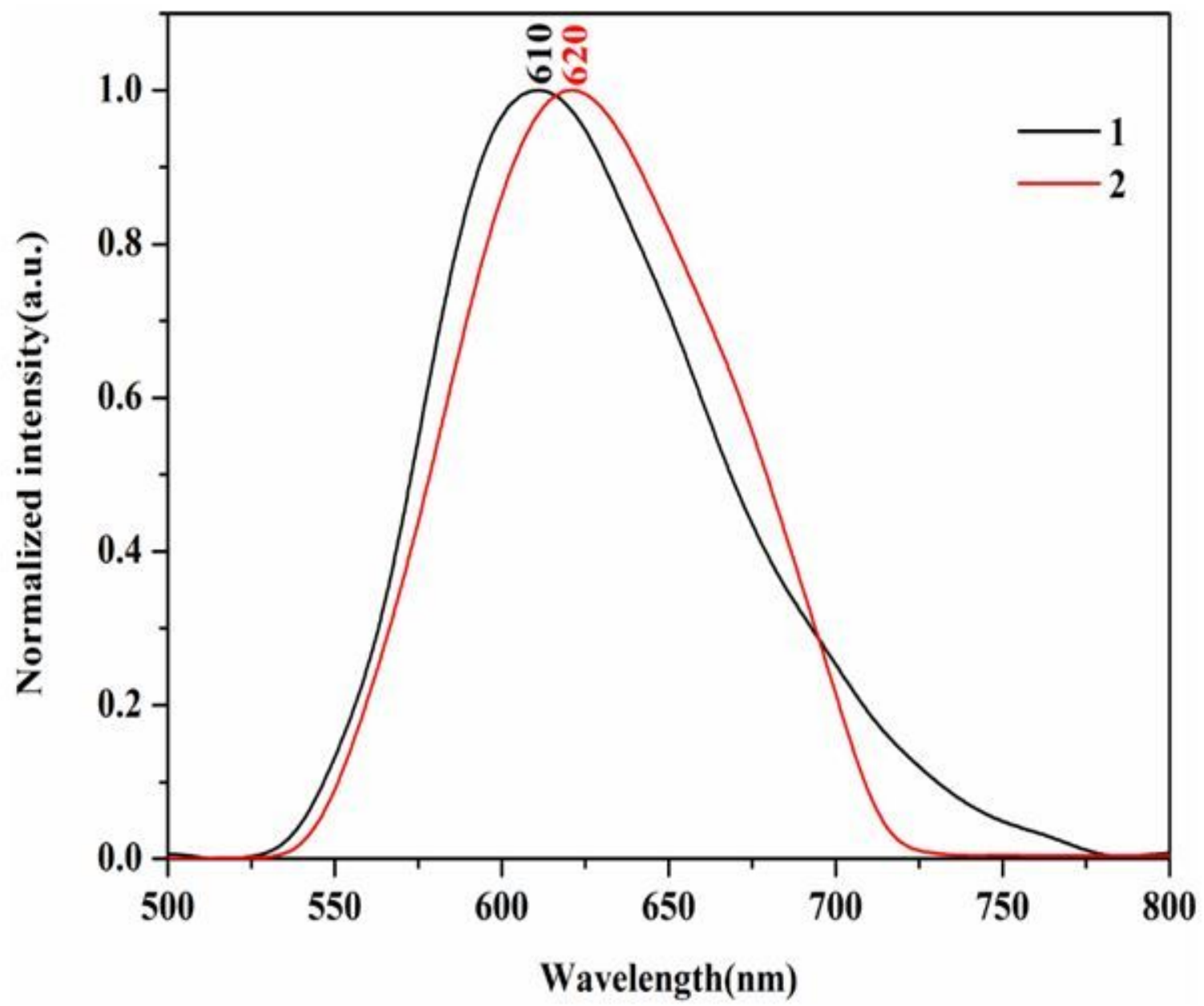

Figure 6

Normalized solid state fluorescence diagram of compound 1 and 2 


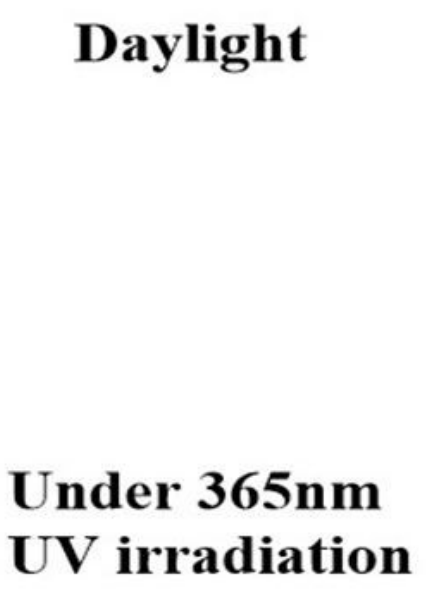

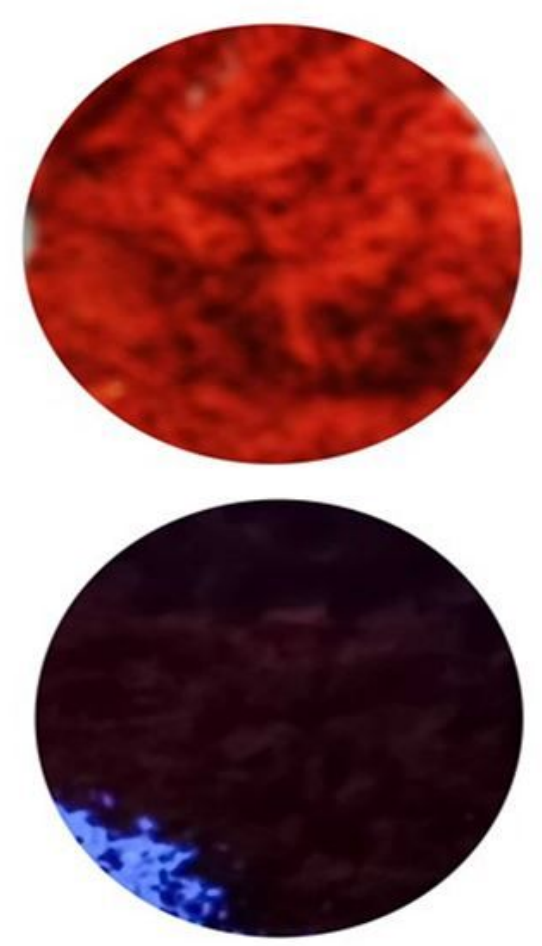

Compound1

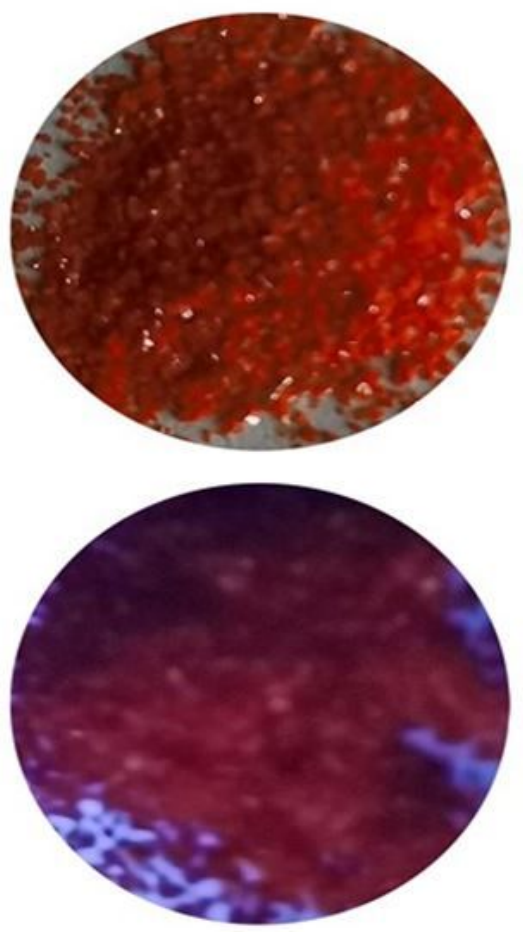

Compound2

Figure 7

Photographs of compound 1 and compound 2 under daylight and 365nm UV irradiation 


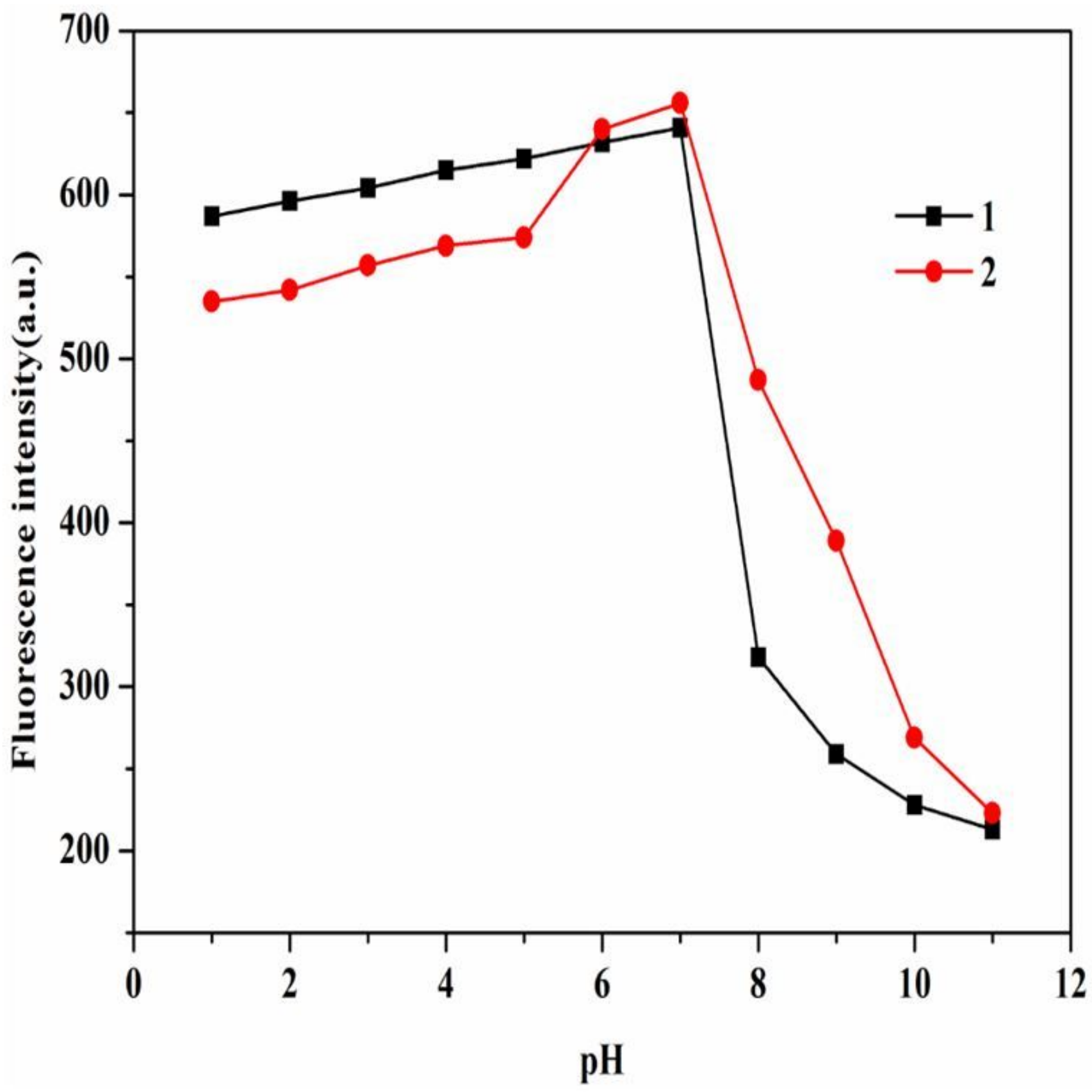

Figure 8

The fluorescence intensity of compound 1 and compound 2 in ethanol/water mixtures ( $f w=90 \%$ ) changes with $\mathrm{pH}$ 

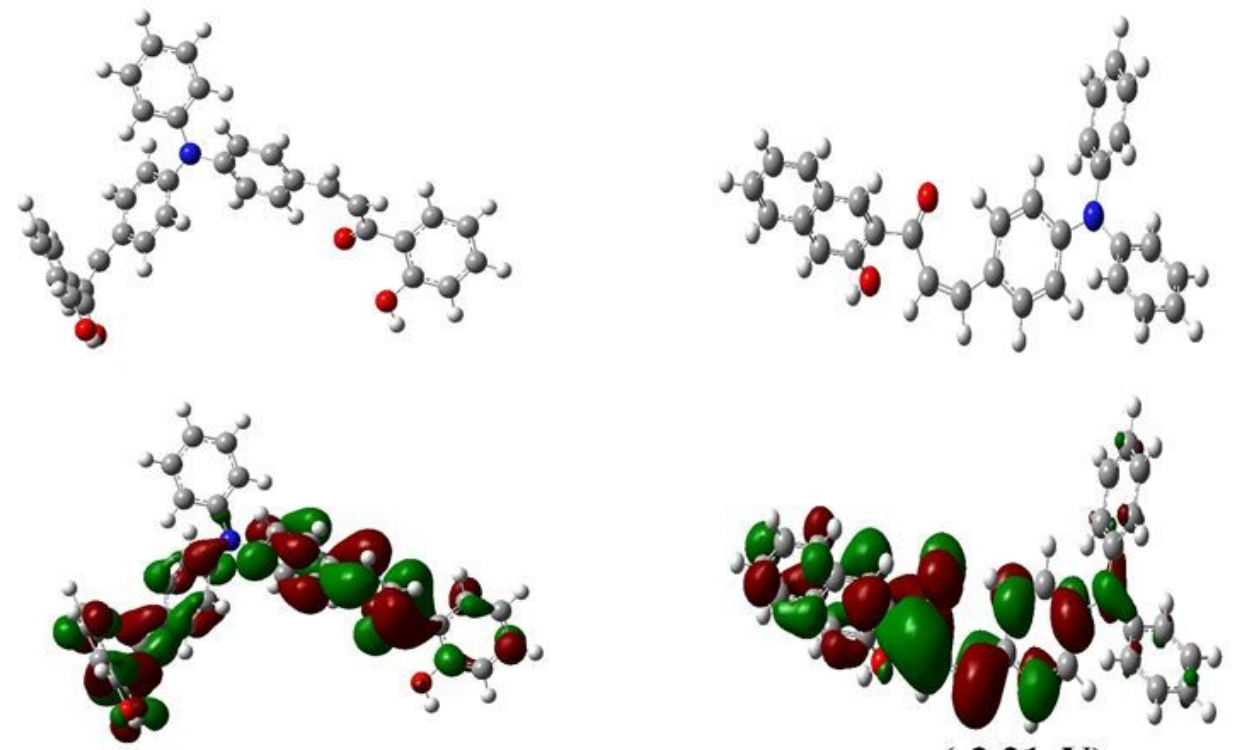

LUMO
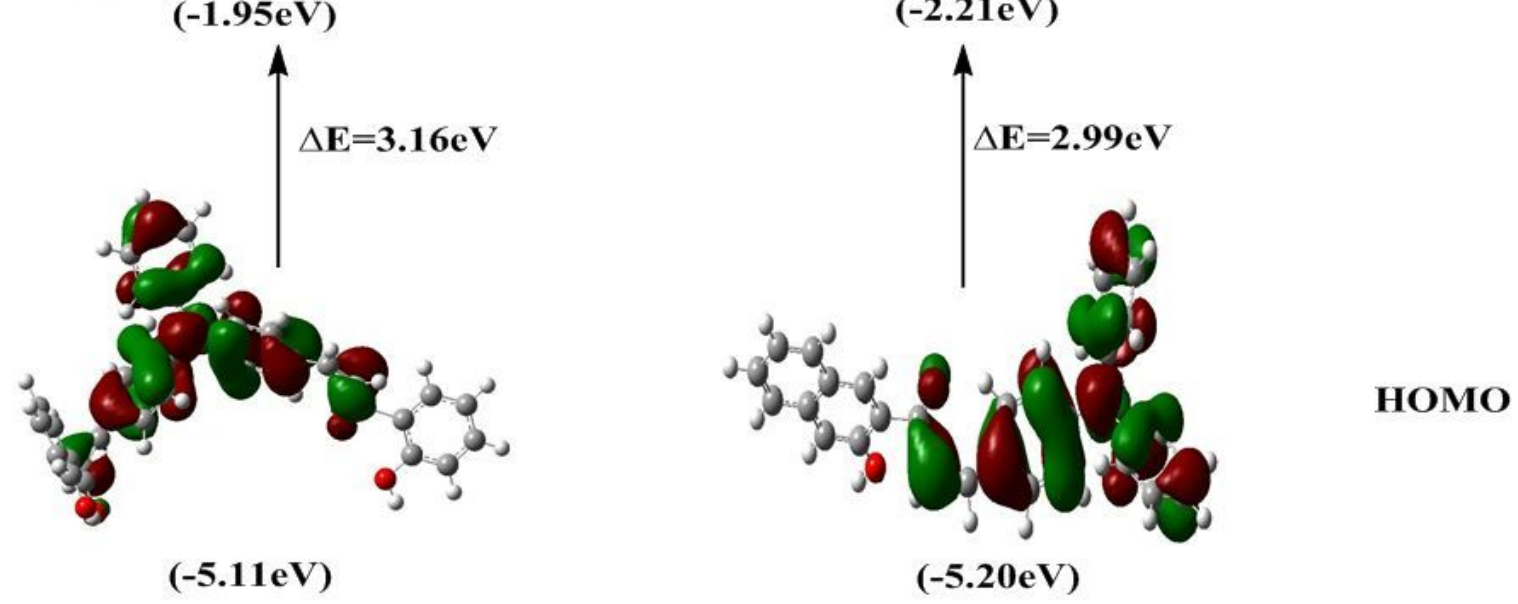

Figure 9

Optimized structure of compound 1 and compound 2, HOMO and LUMO electron cloud distribution 

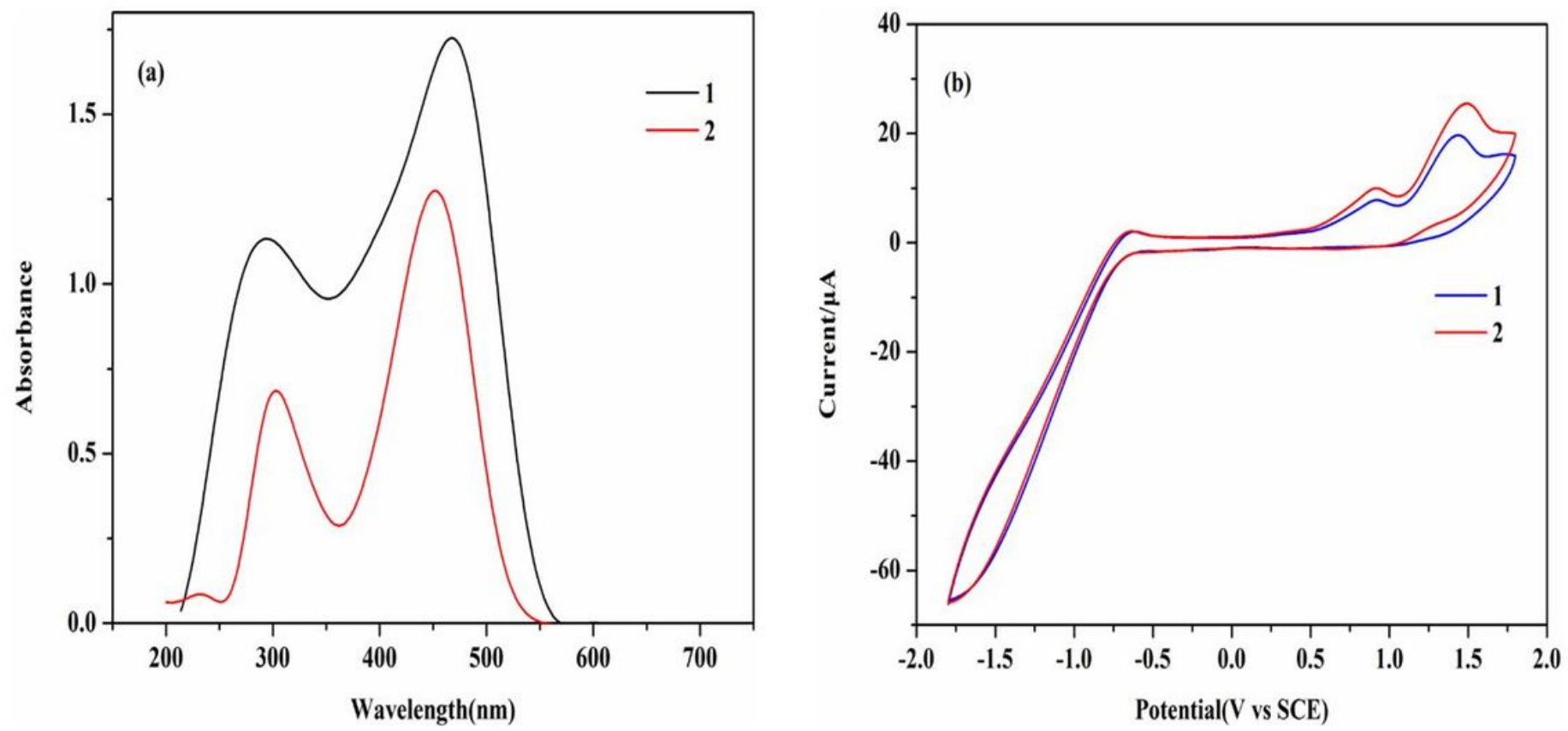

Figure 10

(a) UV-Vis absorption spectra of compounds 1 and 2 in chloroform solution; (b) Cyclic voltammogram of compound 1 and compound 2 in 0.1M Bu4NPF6-CHCl3 


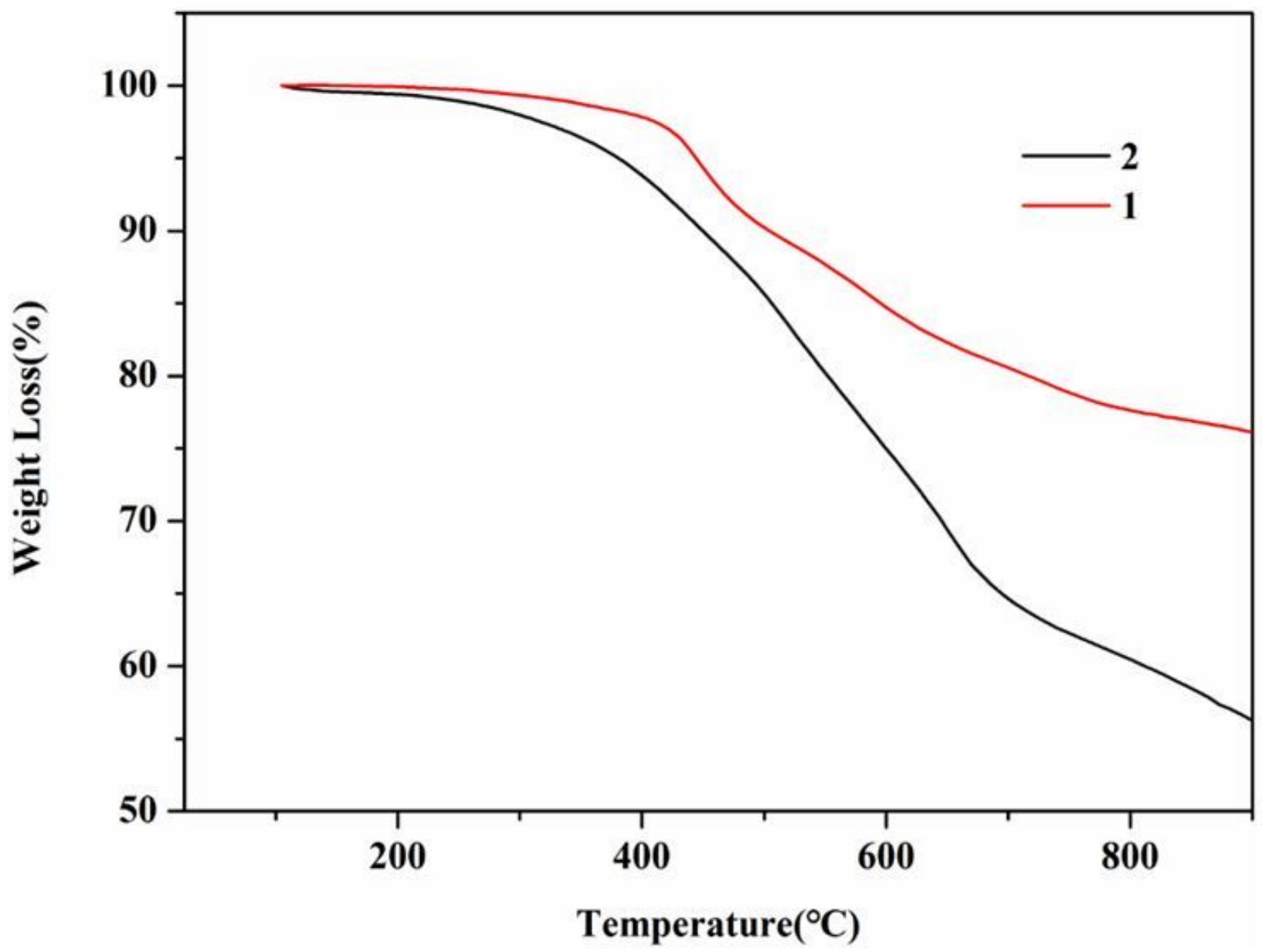

Figure 11

Thermogravimetric analysis of compound 1 and compound 2 